Original Research Paper

\title{
Methadone and Dexmedetomidine Combination as Premedicant Agents for Ovariectomy in Cats
}

\author{
Tayari, H., I. Vannozzi, G. Breghi and A. Briganti \\ Department of Veterinary Sciences, University of Pisa, Pisa, Italy
}

\author{
Article history \\ Received: 23-12-2014 \\ Revised: 19-2-2015 \\ Accepted: $17-6-2015$ \\ Corresponding Auhtor: \\ Hamaseh Tayari \\ Department of Veterinary \\ Sciences, University of Pisa, \\ Pisa, Italy \\ Email: hamasehtayari@gmail.com
}

\begin{abstract}
The purpose of this study was to assess sedative and analgesic effects produced by the association of methadone and dexmedetomidine, administered intramuscularly as premedication for ovariectomy in cats. Twenty-four healthy cats were enrolled in the study. The values of heart and respiratory rate were recorded as Tbase. Cats received methadone 0.5 $\mathrm{mg} \mathrm{kg}$ and dexmedetomidine $5 \mathrm{mcg} \mathrm{kg}^{-1} \mathrm{IM}$. Sedation and ease for catheterization were scored using a simple descriptive scale ranging from 0 (no sedation) to 3 (profound sedation) and 0 (very difficult) to 3 (very easy). General anesthesia was induced with propofol and after endotracheal intubation it was maintained with isoflurane. During the surgery Heart Rate (HR), Respiratory Rate (RR), hemoglobin oxygen saturation, Doppler blood pressure, expiratory isoflurane percentage and end tidal of carbon dioxide were recorded every five minutes. At the end of the surgery all animals received robenacoxib $2 \mathrm{mg} \mathrm{kg}^{-1}$ subcutaneously. Recovery was scored using a simple descriptive scale ranging from 0 (poor) to 3 (excellent). The median sedation score was 2 (range $0-3$ ); the only adverse effect associated with the premedication was vomiting occurred in $20 \%$ of the cats. No animals became excited after premedication. The median ease for catheterization was 3 (range 1-3). After premedication $H R$ and RR showed a decrease of $28 \%$ and of $32 \%$, respectively, in comparison to Tbase values. The median recovery score was 3 (range 1-3). No animal required additional analgesia after the surgery. The association of dexmedetomidine $5 \mathrm{mcg} \mathrm{kg}^{-1}$ and methadone $0.5 \mathrm{mg} \mathrm{kg}^{-1}$ employed in this study resulted in overall good sedation quality without any major adverse reaction. The onset of sedation was quite fast (about $7 \mathrm{~min}$ ), suggesting synergic effect of the two molecules. Most of cats showed an easy catheterization and the recovery was excellent for the majority of cases.
\end{abstract}

Keywords: Methadone, Dexmedetomidine, Sedation, Ovariectomy, Cat

\section{Introduction}

Cats can be difficult to handle and, in veterinary practice, sedation is required for many procedures such as placement of an Intravenous (IV) catheter (Moffat, 2008) or X-rays. Sedative drugs are frequently used as a component of pre-anesthetic medication for cats. Among these, alpha $a_{2}$ adrenergic agonists are a widely used group. They provide deep sedation, muscle relaxation and even analgesia, by acting on nociceptive neural pathways at the spinal cord level and the upper spinal level (Pertovaara, 1993). Dexmedetomidine is a relatively new alpha ${ }_{2}$ adrenergic agonist; it is the active optical enantiomer isolated from the racemic compound medetomidine (MacDonald et al., 1991; Selmi et al., 2003). Efficacy of dexmedetomidine has been demonstrated by several studies in cats (Ansah et al., 1998; Mendes et al., 2003; Granholm et al., 2006) however dexmedetomidine has also important cardiovascular and respiratory side effects, such as peripheral vascular resistance increase, bradycardia, decrease in cardiac output and respiratory depression (Pypendop et al., 2011). These effects are the result of a decrease in sympathetic activity and a simultaneous parasympathetic increase in the Central Nervous System (CNS) plus the vagal reflex originating in the 
baroreceptors in response to the initial hypertension caused by alpha $a_{2}$ agonist. These effects have been demonstrated to be dose dependent (Sinclair et al., 2003).

To reduce the cardiovascular effects and keep or potentiate the sedative effects of alpha ${ }_{2}$ agonists, several authors proposed the combination of these agents with other drugs (Leppänen et al., 2006; Monteiro et al., 2008).

Historically, opioids were not used in cats for many years because of fear of excitement. However, when appropriate doses are used and recommended dosing intervals are respected, opioids can be effectively used to treat acute pain in this species (Taylor and Robertson, 2004). Opioids bind to opioid receptors in the nervous system, inhibiting release of excitatory neurotransmitters in the brain and spinal cord, thereby reducing the pain from nociceptive stimulus (Pascoe, 2000; Wright, 2002). Several studies report the effects of morphine in cats and at clinical doses it does not cause excitement or 'mania' (Robertson et al., 2003). Morphine is useful for treatment of severe pain but it may be less effective in cats than in other species due to limited feline metabolism producing active morphine metabolites (morphine-6-glucuronide) (Taylor et al., 2001; Teppema et al., 2008; Kilpatrick and Smith, 2005). Methadone is a synthetic full agonist opioid, whose chemical structure is unrelated to any of opiumderivate alkaloids (Fishamn et al., 2002). This drug is an agonist at $\operatorname{MOP}(\mu)$ opioid receptors and antagonist at NMethyl-D-Aspartate (NMDA) receptors (Gorman et al., 1997). It also inhibits the reuptake of serotonin and norepinephrine (Codd et al., 1995; Gorman et al., 1997; Fishamn et al., 2002) and promotes the blockade of nicotinic cholinergic receptors (Xiao et al., 2001). The use of methadone in cats may present an advantage over other opioids as it does not undergo glucuronidation and it is less likely to accumulate (Court and Greenblatt, 2000).

In rodents, co-administration of opioid and alpha 2 agonists can produce "greater-than-additive" (i.e., synergistic) analgesic effects (Chabot-Doré et al., 2014).

Evidences, from immunohistochemical studies, suggest that opioid receptors are coexpressed in the same population of sensory neurons as alpha $_{2}$ adrenergic receptors and that antinociceptive synergy requires activation of calcium channels and protein kinase $\mathrm{C}$ (Overland et al., 2009). Physical association between G protein-coupled receptors such as the opioid and adrenergic receptors has been proposed to account for the synergistic effect observed. Such interaction could occur at primary afferent neurons level, the spinal cord and the other sites in the CNS, as well as in the periphery (Jordan, et al., 2003). Although these studies were all performed in rodents, there is no indication that opioidadrenoceptor interactions are subject to species differences (Chabot-Doré et al., 2014). These effects may be achieved at much lower doses of alpha 2 agonist because of additive or synergistic effects of the two agents (Ossipov et al., 1990). This opioid-adrenoceptor synergy can potentially improve analgesic efficacy of opioids and or reduce side effects of alpha $a_{2}$ agonists improving the therapeutic index of both drugs. The clinical application of opioid-adrenoceptor combination therapy is not investigated despite its potential benefits.

The aim of this study was to evaluate the sedation level and analgesic plane produced by the association of methadone and dexmedetomidine as premedication prior to neutering in healthy cats.

\section{Materials and Methods}

\section{Animals}

The study was conducted in compliance with the European Welfare Act and with the approval of Ethical Committee of the University of Pisa (Protocol $\mathrm{N}^{\circ} 984$ 26/01/2009).

Twenty-four females client-owned domestic shorthaired cats scheduled for elective ovariectomy were enrolled in the study. Before starting the procedure, a full clinical anamnesis and a complete examination (which consisted of physical examination, plus a hematological and serum biochemical analysis) were carried out. Only cats ranked as American Society of Anesthesiologists classification system (ASA) physical status 1 (normal healthy patient with no detectable disease) were included in the study. Written informed consent was obtained from the owners before the participation of any cat in the study.

\section{Treatment and Assessments}

\section{Premedication}

The cats were fasted by owners for $12 \mathrm{~h}$ with free access to water until pre-anesthetic medication was administered. On the day of surgery each cat was weighted and underwent a physical examination. Heart Rate (HR) and Respiratory Rate (RR) in awakes cats were registered as Tbase values. HR was assessed by auscultation, respiratory rate $\mathrm{RR}$ was assessed by observing chest expansion. Mucous membrane color was subjectively graded as normal, pale, cyanotic or injected and capillary refill time was assessed. Animals were checked for pain using a Visual Analogue Scale (VAS). After the Tbase data collection all the cats received a preanesthetic medication that consisted in dexmedetomidine (500 mcg $\mathrm{mL}^{-1}$; Dexdomitor, Orion Corporation, Espoo, Finland) at a dose of $5 \mathrm{mcg} \mathrm{kg}^{-1}$ and methadone $0.5 \mathrm{mg}$ $\mathrm{kg}^{-1}$ (10 mg mL ${ }^{-1}$; Semfortan, Eurovet Animal Health, Bladel, Holland) in the same syringe injected into the gluteal or the longissimus dorsi muscle. In case of sedation was not obtained after $15 \mathrm{~min}$, a bolus of $5 \mathrm{mcg}$ $\mathrm{kg}^{-1}$ of dexmedetomidine was administered IM and afterward the case was excluded from the study. 
Table 1. Simple descriptive scale for sedation score after premedication

\begin{tabular}{lll}
\hline Score & Classification & Descriptors \\
\hline 0 & No sedation & Cat bright, alert, responsive, moving around \\
1 & Mild sedation & Cat relaxed, but can be roused and can walk with little or no ataxia \\
2 & Moderate sedation & Cat in sternal or lateral recumbency, but can be roused and has obvious signs of ataxia \\
3 & Profound sedation & Cat recumbent and no response to stimulation \\
\hline
\end{tabular}

Table 2. Simple descriptive scale for ease of intravenous catheter placement

\begin{tabular}{lll}
\hline Score & Classification & Descriptors \\
\hline 0 & Very difficult & Impossible to perform IV catheterization or cat requires a lot of restraint, multiple attempts required \\
1 & Difficult & Cat requires good restraint, trying to move \\
2 & Easy & Minimal restraint required \\
3 & Very easy & Cat recumbent and not responding to stimulation \\
\hline
\end{tabular}

Table 3. Recovery scale after general anesthesia

\begin{tabular}{lll}
\hline Score & Classification & Descriptors \\
\hline 0 & Poor & $\begin{array}{l}\text { Cat show major signs of excitement during recovery, thrashing, moving around rapidly, growling, } \\
\text { does not respond to gentle handling }\end{array}$ \\
1 & Moderate & $\begin{array}{l}\text { Cat show some sings of excitement during recovery but responds to gentle handling by calming down } \\
\text { Mild signs of excitement such as growling which resolve quickly so that the cat becomes calm }\end{array}$ \\
3 & Good & Cat is calm and relaxed during recovery
\end{tabular}

Table 4. Scores for sedation, easy to put the venous access and for quality of recovery

\begin{tabular}{lll}
\hline Sedation score Median (range) & Catheter score Median (range) & Recovery score Median (range) \\
\hline $2(0-3)$ & $3(1-3)$ & $3(1-3)$ \\
\hline
\end{tabular}

Incidence of adverse effects, such as salivation and vomiting, were recorded. After the premedication injection, HR and RR were assessed every five minutes and recorded as TPre 5, TPre 10 and so on until the induction was performed.

Time to reach the sedation effect after premedication was recorded as Time from Premedication to Sedation (TPS). Quality of sedation was assessed by observation of behavior by the same clinician and scored using a Simple Descriptive Scale (SDS) as described by Bortolami et al. (2013) "Table 1".

\section{Catheter Placement and Induction}

Using an aseptic technique a cephalic vein was catheterized by the student of the last year of veterinary medicine, subsequently the infusion of Ringer's solution was started at the dose of $5 \mathrm{ml} \mathrm{kg}^{-1} \mathrm{~h}^{-1}$. The ease of restraint for IV catheter placement was assessed with a four point SDS (Bortolami et al., 2013) "Table 2". Time from Premedication to Induction (TPI) was recorded. Afterwards induction was performed with an IV bolus of propofol (Proposure, MerialItalia $\mathrm{SpA}$ ) to effect. Induction was considered complete when, after topic administration of $2 \%$ of lidocaine at the dose of $2 \mathrm{mg} \mathrm{kg}^{-1}$ (Dyson, 1988) on the glottis, orotracheal intubation was feasible.

\section{General Anesthesia and Surgery}

All cats were attached to a non-rebreathing circuit (Mapleson D) and anesthesia was maintained with isoflurane in a mixture of air and oxygen with a fraction of inspired oxygen $\left(\mathrm{FiO}_{2}\right)$ between $60-70 \%$. Immediately after orotracheal intubation, in addition to the previously mentioned clinical parameters; (HR, RR), hemoglobin oxygen saturation $\left(\mathrm{SpO}_{2}\right)$ was measured using a pulseoximeter with lingual probe. End tidal carbon dioxide $\left(\mathrm{EtCO}_{2}\right)$, expired fraction of isoflurane $\left(\mathrm{F}_{\mathrm{E}} \mathrm{Iso}\right)$ and temperature $\left(\mathrm{C}^{\circ}\right)$ were measured continuously and recorded every $5 \mathrm{~min}$ until the end of the procedure with a multiparametrical monitor (Mindray Beneview T5, China). Noninvasive arterial blood pressure was measured using the Doppler technique (DBP), (Doppler flow detector, Parks Medical Electronics, NV, USA). The hair was clipped from the palmar aspect of foot and the Doppler probe was placed over the common digital branch of the radial artery. Aqueous gel was placed between the probe and the skin to ensure contact. The probe was secured with adhesive tape and the volume of the Doppler was adjusted to obtain a clear signal. A cuff's width approximately $40-60 \%$ of the diameter of the limb was used to measure continuously and recorded each 5 min the DBP values.

All parameters recorded five minutes before the start of the surgery ( $\mathrm{HR}, \mathrm{RR}, \mathrm{DBP}, \mathrm{SpO}_{2}, \mathrm{EtCO}_{2}, \mathrm{~T}^{\circ}, \mathrm{F}_{\mathrm{E}}$ Iso) were registered as T0 values. Surgery was always performed by the same surgeon (VI), using a standard midline abdominal approach. Increase of more than $20 \%$ of HR and DBP was considered as nociception response and a rescue analgesia with a bolus of $2 \mathrm{mcg} \mathrm{kg}^{-1}$ of fentanyl IV was administered (Fentanest $0.05 \mathrm{mg} \mathrm{mL}^{-1}$, 
Actavis Italy S.p.A., Nerviano, Italy, distributed by Pfizer). If more than two boluses were required to reestablish the cardiorespiratory parameters, a variable rate fentanyl infusion (2.5-10 $\mathrm{mcg} \mathrm{kg}^{-1} \mathrm{~h}^{-1}$ ) started. During the surgery the anesthetic plane was maintained decreasing the expired fraction of isoflurane ( $F_{E}$ Iso) of $0.1-0.2 \%$ each $5 \mathrm{~min}$ in order to achieve the minimal concentration necessary to prevent movement; in case of movements an IV bolus of propofol at the dose of $2 \mathrm{mg}$ $\mathrm{kg}^{-1}$ was administered and the $\mathrm{F}_{\mathrm{E}}$ Iso increased of $0.1-0.2 \%$. In case of DBP $<80 \mathrm{mmHg}$ a bolus of $2 \mathrm{~mL} \mathrm{~kg}^{-1}$ of colloids was administered IV. If the DPB was not increased dopamine at the range dose of 2-5 $\mathrm{mcg} \mathrm{kg}^{-1} \mathrm{~h}^{-1} \mathrm{IV}$ was administered. Total anesthesia time, from induction to the discontinuation of isoflurane (TAT) was recorded.

\section{Recovery}

At the end of surgery, isoflurane was discontinued and a bolus of atipamezole (Alzane $5 \mathrm{mg} \mathrm{mL}^{-1}$, SYVA S.A., Leon, Spain, distributed by Pfizer) at the dose of $25 \mathrm{mcg} \mathrm{kg}^{-1}$ was administered intramuscularly. Cats were extubated when the swallowing reflex had completely returned. Afterward $2 \mathrm{mg} \mathrm{kg}$ of robenacoxib was administered subcutaneously.

The quality of recovery after general anesthesia was assessed by a simple descriptive scale (Bortolami et al., 2013 "Table 3". The pain evaluation was performed during the first hour after surgery; after that cats were discharged from the hospital. Any adverse event occurred during the recovery was recorded.

\section{Statistics}

Data were analyzed for normal distribution with D'Agostino \& Pearson test. For normally distributed data, mean \pm standard deviation is reported. For nonparametric data, median and range is reported. Clinical parameters were analyzed throughout the monitored time points with a one-way ANOVA with a Tukey post hoc test and the initial values (T0) were compared to all the subsequent time points using a one way ANOVA with a Dunnett's post hoc test.

Non-parametrical data were analyzed with a KruskalWallis test. Values of $\mathrm{p}<0.05$ were considered significant. GraphPad Prism software (GraphPad Software, Inc., La Jolla, USA) was used for the statistical analysis.

\section{Results}

All cats completed the study without any major complications. Two cats were removed from the study after enrollment as a second bolus of dexmedetomidine, $5 \mathrm{mcg} \mathrm{kg}^{-1} \mathrm{IM}$, was administered to obtain sedation. Population data were homogenous in terms of age and weight. The mean age and weight of cats resulted $20.3 \pm 12.8$ months and $3.2 \pm 0.5 \mathrm{~kg}$ respectively. Emesis was noted in $5 / 24$ cats after premedication. No animals became excited after pre-anesthetic medication. No adverse events were observed during the recovery.

All cats were pain free at the start of the study and prior to anesthetic induction (VAS $=0 \mathrm{~cm})$. The median score for quality of sedation was 2 , ranging from $0(2 / 24$ cats) to $3(7 / 24$ cats).

Mean time and SD for the following timings were assessed: TPS was $6.9 \pm 3.7 \mathrm{~min}$, TPI was $15.7 \pm 5.1$ min, TAT was $51 \pm 21 \mathrm{~min}$ The median score for catheter placement was 3 , ranging from 1 (1/22 cats) to $3(16 / 22$ cats). The median score for quality of recovery after general anesthesia was 3 , ranging from $1(2 / 22$ cats $)$ to $3(12 / 22)$ "Table 4 ".

\section{Baseline and Premedication}

The mean \pm SD values of Tbase were 164.4 \pm 23.51 beats per minute (bpm) for HR and $35.3 \pm 15.6$ breaths per minute (bpm) for RR. Baseline values of HR resulted significantly different in comparison to all the subsequent values after premedication. Regarding RR only the values recorded at T20 resulted significantly lower than Tbase values "Fig. 1".

\section{Induction, General Anesthesia and Surgery}

Induction of anesthesia and endotracheal intubation were achieved without complication and anesthesia was maintained uneventfully in all cases. The mean induction dose of propofol was $1.5 \pm 0.8 \mathrm{mg} \mathrm{kg}^{-1}$. During surgery a bolus of propofol, $2 \mathrm{mg} \mathrm{kg}^{-1} \mathrm{IV}$, was administered in $2 / 22$ cats. Mean intraoperative dosage of propofol was $0.45 \pm 0.16 \mathrm{mg} \mathrm{kg}{ }^{-1}$. $\mathrm{F}_{\mathrm{E}}$ Iso values registered at $\mathrm{T} 10$ resulted significantly lower in comparison to $\mathrm{T} 0$ values "Fig. 2". No statistically significant differences were detected at any time point during anesthesia for HR, RR, DBP, $\mathrm{EtCO}_{2}$ and $\mathrm{SpO}_{2}$ (data not shown for the $\mathrm{SpO}_{2}$ ), "Fig. 3-6". During surgery 18/22 cats breathed spontaneously, 7/22 cats required assisted ventilation and $5 / 22$ cats required control ventilation to maintain the $\mathrm{EtCO}_{2}$ values between $35-40 \mathrm{mmHg}$. Some cats received more than one type of ventilation. During surgery 1 cat received one bolus of colloids $2 \mathrm{~mL} \mathrm{~kg}^{-1}$ and 1 cat received a dopamine infusion for $15 \mathrm{~min}$ at $2 \mathrm{mcg}$ $\mathrm{kg}^{-1} \mathrm{~min}^{-1} \mathrm{IV}$, to maintain DBP values $\geq 80 \mathrm{mmHg}$. Atropine as a bolus was necessary in 1 cat to contrast bradycardia and hypotension. During the surgery 9/22 cats required fentanyl rescue analgesia as a bolus of 2 mcg $\mathrm{kg}^{-1}$; one bolus was adequate in $7 / 9$ cats. One cat received two boluses of fentanyl and one cat required a fentanyl infusion at the dose of $2.5 \mathrm{mg} \mathrm{kg}^{-1} \mathrm{~h}^{-1}$. Mean intraoperative dosage of fentanyl was $0.8 \pm 1.2 \mathrm{mcg} \mathrm{kg}^{-1}$. 


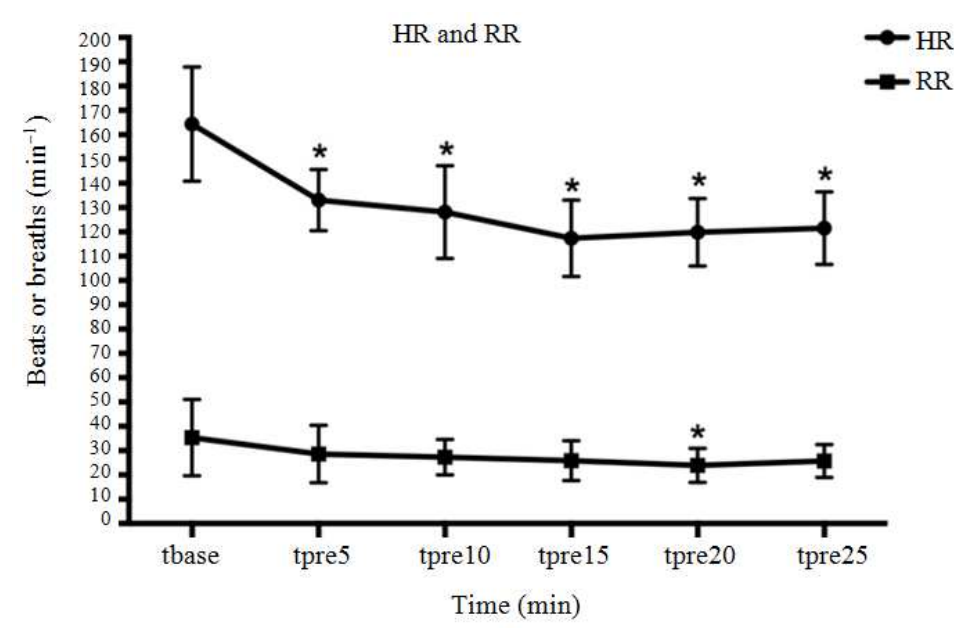

Fig. 1. Mean values and standard deviation of HR and RR, before premedication (Tbase) and for the 25 subsequent minutes; * significantly different from Tbase values

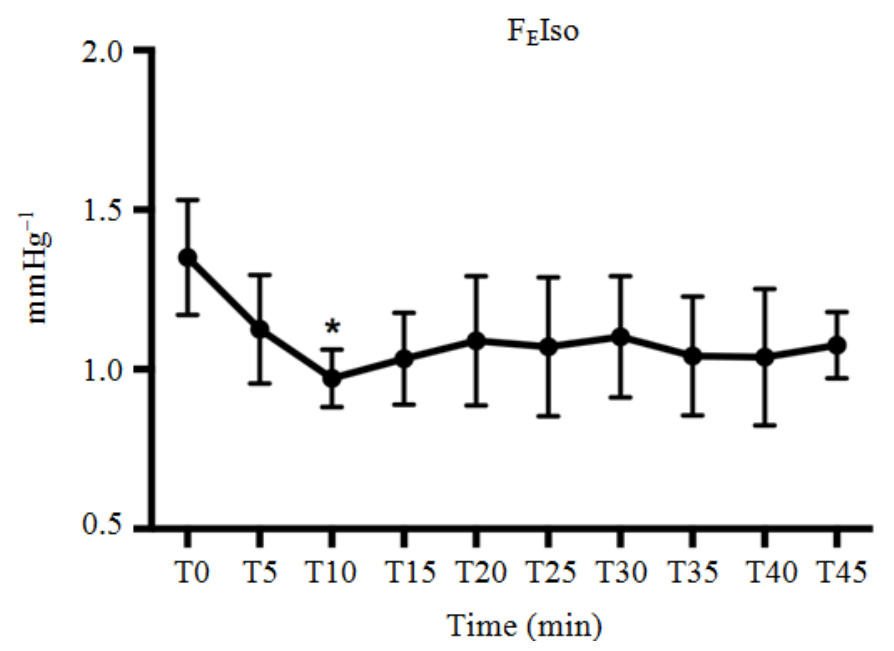

Fig. 2. Mean values and standard deviation of $\mathrm{F}_{\mathrm{E}}$ Iso during the surgery; * significantly different from $\mathrm{T} 0$

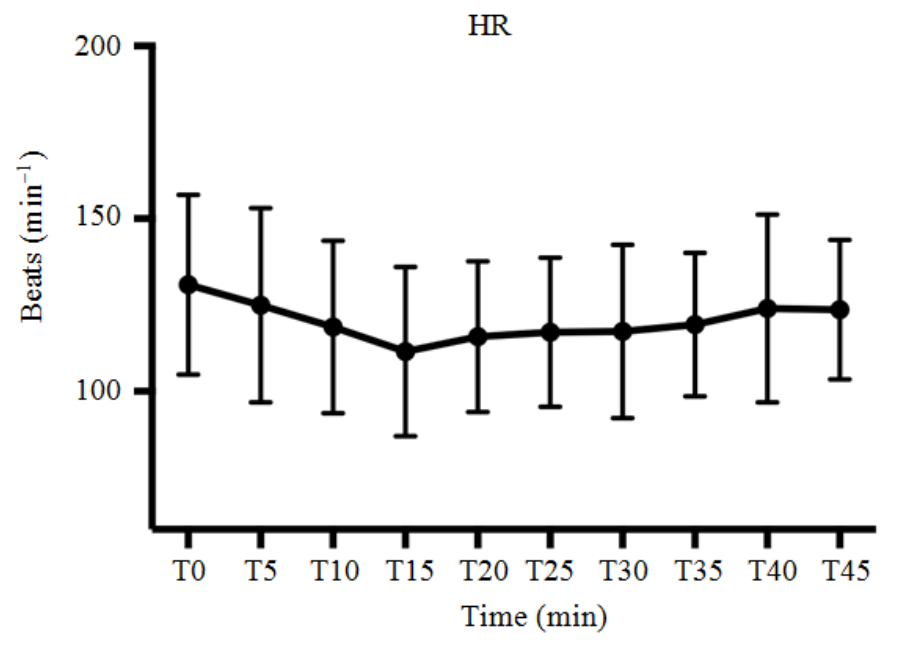

Fig. 3. Mean values and standard deviation of HR during the surgery 


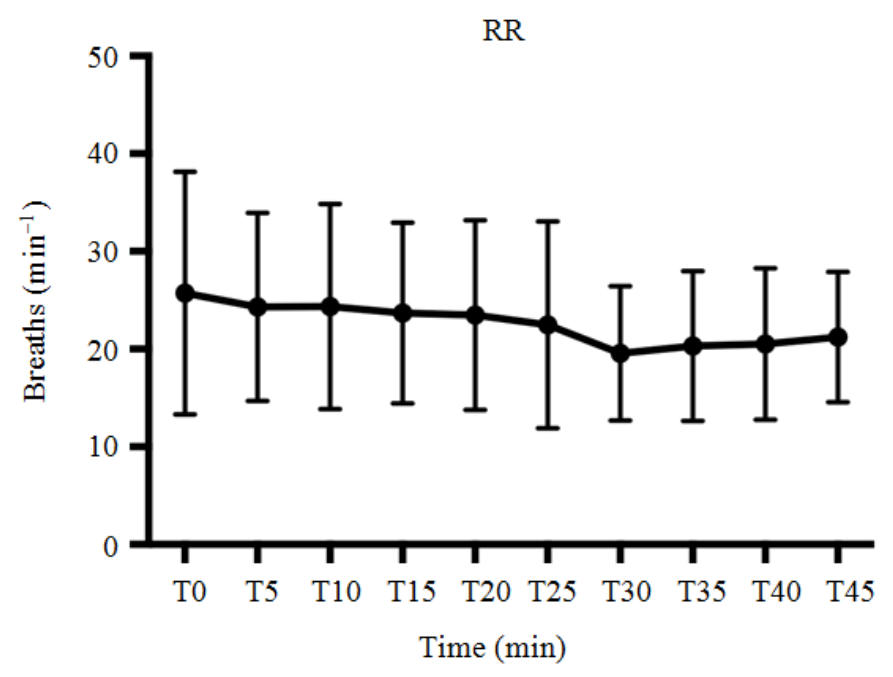

Fig. 4. Mean values and standard deviation of RR during the surgery

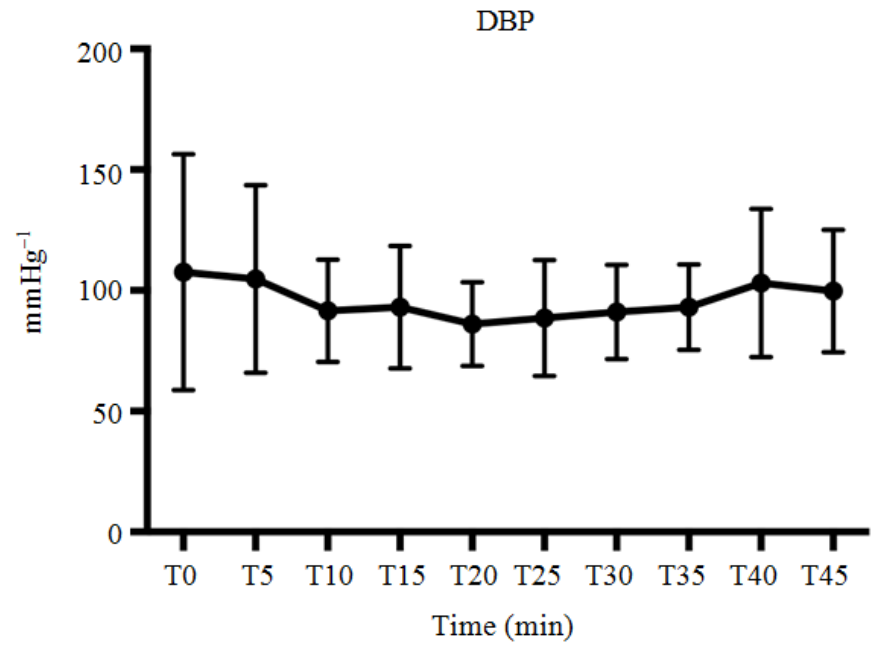

Fig. 5. Mean values and standard deviation of blood pressure measured by Doppler technique (DBP) during the surgery

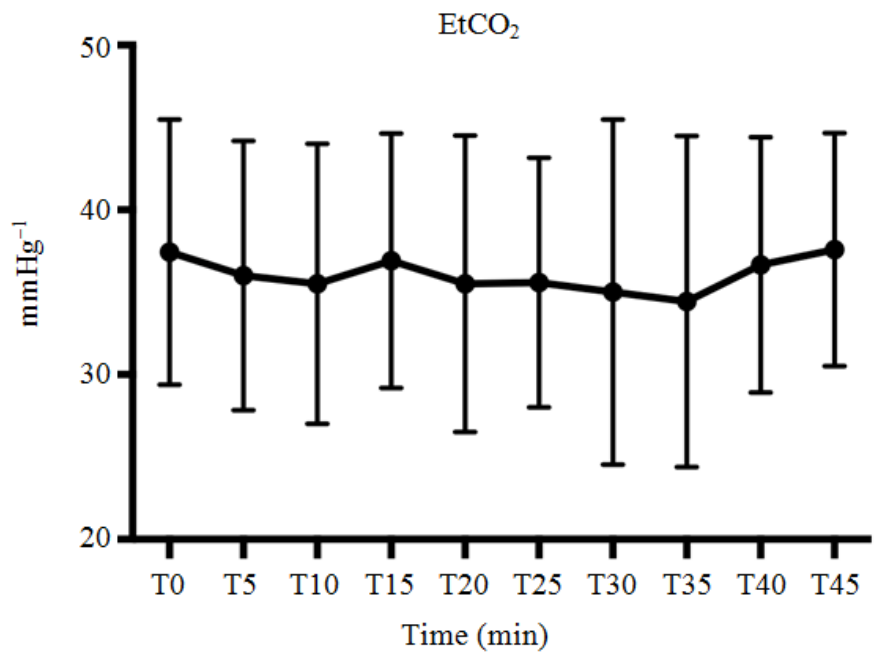

Fig. 6. Mean values and standard deviation of End tidal Carbon Dioxide $\left(\mathrm{EtCO}_{2}\right)$ during the surgery 


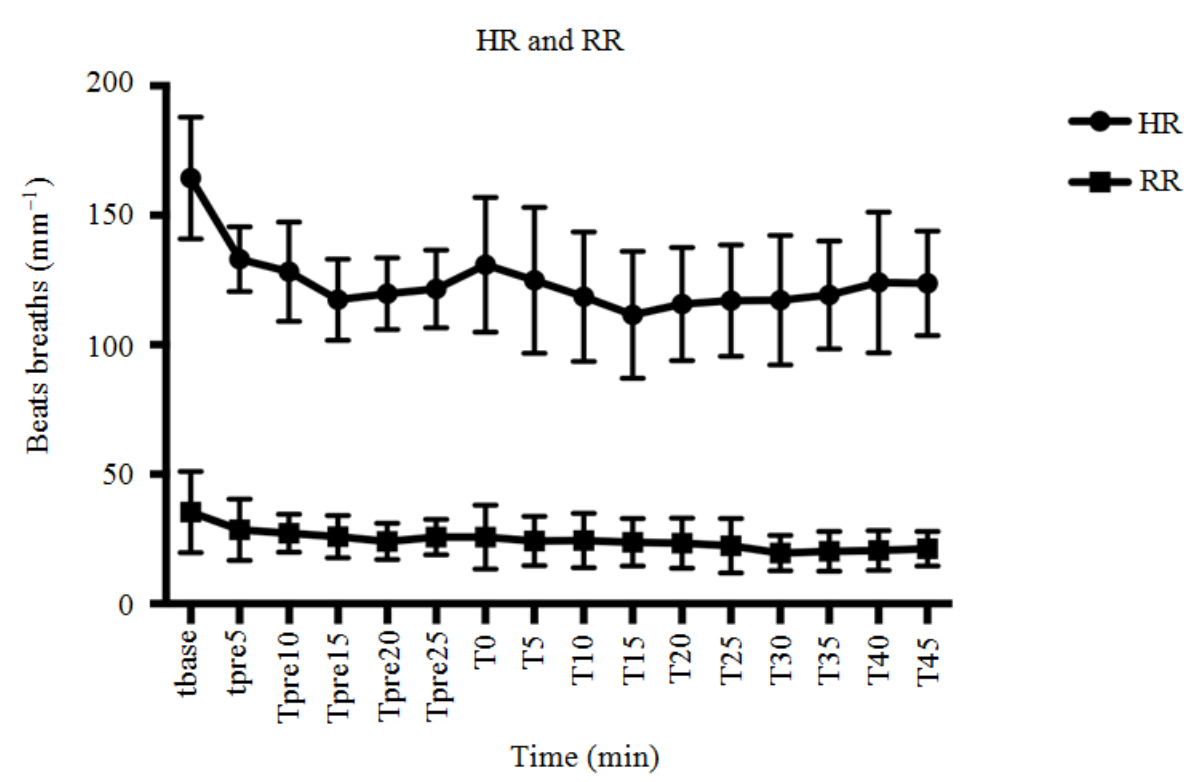

Fig. 7. Heart Rate (HR) and Respiratory Rate (RR) before and during surgery

\section{Recovery}

At the end of the surgery $14 / 22$ cats received atipamezole $25 \mathrm{mcg} \mathrm{kg}^{-1} \mathrm{IM}$. Postoperative recovery score was good to excellent for most animals. Median recovery score was 3 ranging from $1(1 / 22)$ to $3(12 / 22)$. No animals required additional analgesic medication during recovery.

\section{Discussion}

The association of dexmedetomidine $5 \mathrm{mcg} \mathrm{kg}^{-1}$ and methadone $0.5 \mathrm{mg} \mathrm{kg}^{-1}$ employed in this study resulted in overall good quality sedation without any major adverse reaction. The onset of the sedation was quite fast (about $7 \mathrm{~min}$ ) and most of animals showed a sedation score of 2 (cat in sternal or lateral recumbency, but can be roused and has obvious signs of ataxia), suggesting synergic effect of the two molecules.

Cats may be a challenge in veterinary practice due to their small size, agility and tendency to be stressed by handling for medical procedures. Sedation prior to general anesthesia is often required to facilitate the anesthetic induction process and prevent the feline patient becoming stressed, which may adversely affect the course of anesthesia.

In this study the association between dexmedetomidine and methadone allowed to handle cats easily in the majority of the cases and only in two cases a second bolus of dexmedetomidine $5 \mathrm{mcg} \mathrm{kg} \mathrm{kg}^{-1} \mathrm{IM}$ was necessary to achieve a good sedation. The reasons of these lacks of sedation might be explained by individual variability. Stress and anxiety may have an influence on the sedative effect of dexmedetomidine because of the competitive nature of adrenaline at the adrenoreceptors site (Grint et al., 2009). Another potential cause of variation after treatment is pharmacokinetic variability due to different absorption of the drug after intramuscular administration. In a relatively recent study cats that received $40 \mathrm{mcg} \mathrm{kg}^{-1} \mathrm{IM}$ of dexmedetomidine became all fully sedated (i.e., flat out and no response to a noise, VAS $=100$ ) for a period longer than $15 \mathrm{~min}$ (Granholm et al., 2006). The dose chosen in the present study ( $5 \mathrm{mcg} \mathrm{kg}^{-1} \mathrm{IM}$ ) was very low, in order to establish whether the combination of methadone and low dosage of dexmedetomidine could produce a synergistic effect. A recent study showed that methadone at the dose of 0.5 $\mathrm{mg} \mathrm{kg}^{-1}$ in combination with acepromazine $0.05 \mathrm{mg} \mathrm{kg}^{-1}$ as premedication in cat provided similar sedative effect than that produced by buprenorphine plus acepromazine and butorphanol plus acepromazine (Bortolami et al., 2013). From that study emerged that in all the cats was possible to place the venous access and the median and range score was $2(0-2)$. In the present study we adopted the same SDS and the catheter placement score resulted higher [3(1-3)]; this might be due to the more sedative effect of dexmedetomidine in comparison to acepromazine when combined to methadone. The venous catheterization, in the present study, was performed by the last grade veterinary students and for many of them it was their first experience with cats. As far as we concern, this scenario could be a good test of degree of sedation. In another study (Santos et al., 2010) the association between dexmedetomidine $20 \mathrm{mcg} \mathrm{kg}^{-1}$ and buprenorphine $20 \mathrm{mcg} \mathrm{kg}^{-1}$ IM required a supplemental 
ketamine bolus ( $5 \mathrm{mg} \mathrm{kg}^{-1} \mathrm{IM}$ ) administration in $16 \%$ of cats, in order to achieve catheterization. Bley et al. (2004) demonstrated that IM methadone at the dose of $0.6 \mathrm{mg} \mathrm{kg}{ }^{-1}$ did not produce dysphoria in any cat and after this premedication $7 / 19$ cats did not show behavior changes, 8/19 became purring and affectionate and 5/19 were more difficult to be restrained and the overall reported reaction to venipuncture ranged from passive acceptance to moderate resistance. According to literature (Dobromylskyj, 1993; Bley et al., 2004) methadone $0.5 \mathrm{mg} \mathrm{kg}^{-1} \mathrm{IM}$ as premedication did not produce excitement. The level of sedation and the ease for catheterization we recorded in this study is in accordance with the results of Dobromylskyj (1993). The author used the same dosage of methadone employed in the present study as the only premedication agent and the results showed cats calm in the basket, accepting the lifting from the basket and passive to the restraint for cephalic venipuncture in most cases. The majority of the cats in our study too showed a complete disinterest to the ambient after premedication. The results of these studies (Dobromylskyj, 1993; Rohrer Bley et al., 2004; Santos et al., 2010) could be suggest that the use of high dose of dexmedetomidine is not as fundamental as the use of high dose of methadone to obtain the good handling of cats during the venous catheter placement.

The major side effect noted in the present study after premedication was vomiting as it was observed in $20 \%$ of cases (5/24 cats). Emesis frequently occurs after alpha $_{2}$ agonists administration to cats (Belda et al., 2009); this can distress the animal and increase the risk of aspiration pneumonia. The reported incidence of vomiting after IM dexmedetomidine injection in cats ranged from $8 \%$ to $90 \%$ (Granholm et al., 2006; Slingsby and Taylor, 2008). The big difference in the incidence of vomiting among the studies has not been cleared: it seems it could depend on the fasting period of animals or the different dosage of dexmedetomidine. Some authors report 53\% of incidence of vomiting when dexmedetomidine $20 \mathrm{mcg}$ $\mathrm{kg}^{-1}$ was associated to buprenorphine $20 \mathrm{mcg} \mathrm{kg}^{-1} \mathrm{IM}$ (Santos et al., 2010). Vomiting or salivation are relatively common after morphine and hydromorphone administration. Opioids are considered to stimulate the chemoreceptor trigger zone for emesis in the medulla. Highly lipophilic opioids are less likely to induce vomiting compared to more hydrophilic drugs such as morphine (Steffey and Mama, 2007). Results from a previous study showed that methadone at the dose of $0.6 \mathrm{mg} \mathrm{kg}^{-1} \mathrm{IM}$ did not cause vomit in any cat (Bley et al., 2004). The fasting of about 12 $\mathrm{h}$ and the association of dexmedetomidine with a lipophilic opioid, like methadone, might be the explanation of the relatively low incidence of vomit in our study.
Compared with awakes values (Tbase), decrease in HR was observed after the premedication in all cats "Fig. 1". As reported in previous studies (Kallio et al., 1989; Ansah et al., 1998; Lamont et al., 2001; Mendes et al., 2003; Selmi et al., 2003) marked decrease in heart rate and cardiac output, increase in total vascular resistance and transient mild changes in blood pressure, are expected dose-dependent effects of dexmedetomidine administration. The effect of alpha $a_{2}$ agonist on blood pressure are defined by two stages: An initial phase characterized by peripheral vasoconstriction, increase blood pressure and reflex bradycardia and another subsequent phase with a reduction of sympathetic tone and hypotension (Herbert et al., 2007). Unfortunately blood pressure readings by Doppler technique before induction was not achievable in all cats because this procedure was tolerated only in two awake cats. Arterial blood pressure was registered only after the induction and this did not allow to establish if a hypertensive phase occurred after dexmedetomidine administered IM as premedication. Although no case of pale mucous membranes and weaker femoral pulse were observed after the premedication, we could not exclude the presence of peripheral vasoconstriction during the TPS. In the present study a hypertensive phase was not detected during general anesthesia (TAT) probably because of the moderate dose $\left(5 \mathrm{mcg} \mathrm{kg}^{-1}\right)$.

No changes in HR have been reported following methadone administration IM or SC $\left(0.3\right.$ and $0.6 \mathrm{mg} \mathrm{kg}^{-1}$, respectively) in cats (Mollenhoff et al., 2005; Bley et al., 2004). In the present study, HR values registered $20 \mathrm{~min}$ after injection decreased of about $28 \%$ in comparison to Tbase values, whilst during the intraoperative period no further decrease in heart rate was detected.

Respiratory depression is considered the most serious potential complication due to opioids administration, but according to previous studies (Dobromylskyj, 1993; Bley et al., 2004), methadone administration seems not to significantly depress respiratory parameters. In the present study, the decrease in respiratory rate registered up to $20 \mathrm{~min}$ after injection, "Fig. 1" $(32 \%$ in comparison to Tbase values) could be due to the summation of effects of both drugs used in premedication. Values of HR and RR were significantly decreased during anesthesia compared to awake values (Tbase) but not between induction and general anesthesia, "Fig. 7". Indeed some authors reported, the combination of alpha 2 agonist with opioids are desirable because they can potentiate the sedative and analgesic effects with minimal further cardiovascular effects (Dart, 1999).

The association of the two drugs showed a good sparing effect on the dose of propofol for the induction that was $1.5 \pm 0.8 \mathrm{mg} \mathrm{kg}^{-1}$ instead of $4-10 \mathrm{mg} \mathrm{kg}^{-1}$ as reported in literature (Bednarski, 2011). 
The amount of isoflurane required to maintain anesthesia was consistently less than $1.71 \pm 0.07 \%$ "Fig. 2", the average MAC reported recently for the cat (Shaughnessy and Hofmeister, 2014). The low dose isoflurane requirement was most likely attributable to the sedative and analgesic effects obtained with dexmedetomidine and methadone as premedication.

During the surgery $9 / 22$ cats required fentanyl as one bolus of $2 \mathrm{mcg} \mathrm{kg}^{-1}$ IV to maintain the analgesic plane enough for the procedure. This may indicate that the analgesic plane was not enough for this kind of surgery in $40.9 \%$ of the cats. The dexmedetomidine dose recommended in cats by the manufacturer and approved by EMEA (2009) is $40 \mathrm{mcg} \mathrm{kg}^{-1} \mathrm{IM}$. Administration of this dose resulted in clinically relevant sedation and analgesia, with a nociceptive thresholds increase (Granholm et al., 2006). Slingsby et al. (2009) demonstrated that lower doses of dexmedetomidine (2, $5,10,20 \mathrm{mcg} \mathrm{kg}{ }^{-1}$ ) do not show antinociceptive effects when studying thermal antinociception and only submaximal sedation can be achieved. This may be related to receptor occupancy, as there may be a critical degree of occupancy before antinociceptive effects are triggered. This might explain the need for fentanyl rescue in a high percentage of our animals, as the analgesic plane was mainly supported by methadone. Most of rescue analgesia was administered in relation to the stretching of the first ovarian ligament; this could be related to inadequate analgesic level or anesthetic plane or both at the moment of the ovarian manipulation. The addition of other drugs with analgesic properties, like ketamine or NSAIDs, could avoid to apply for opioids rescue in the intraoperative period as reported in a recent study (Staffieri et al., 2013).

Recovery score was excellent in most of the cases. At the end of the surgery the $63 \%$ of cats received atipamezole at the dose of $25 \mathrm{mcg} \mathrm{kg}$ IM. The remaining $37 \%$ did not receive it because the recovery was very fast after discontinuation of isoflurane. Afterwards no animals required sedation during the recovery but all the cats received robenacoxib $2 \mathrm{mg} \mathrm{kg}^{-1}$ $\mathrm{SC}$ in order to cover the peripheral inflammatory pathway of pain that is reported to be predominant the first 24 hours after the ovariohysterectomy (Staffieri et al., 2013). A limit of the present study was that only the first hour after the surgery has been considered. It could have been interesting to follow cats for longer time in order to assess the analgesic effect of the protocol used.

\section{Conclusion}

In conclusion, the administration of

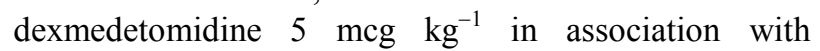
methadone $0.5 \mathrm{mg} \mathrm{kg}^{-1}$ resulted in a good sedation, enabling stress-free handling and easy venous catheterization of cats. The analgesic plane obtained was considered good. The association with a NSAID is expected to improve the efficacy even in the postoperative period.

\section{Acknowledgement}

The authors thank to the student of the 5th years of Veterinary Medicine of Pisa University for the technical assistance.

\section{Funding Information}

This study was carried out by University of Pisa (Athenaeum ex 60\%). Any external funding did not support the preparetion of manuscript.

\section{Author's Contributions}

H. Tayari: Participated in all experiments, performed the in vivo study, the data-analysis and contributed to the writing of the manuscript.

I. Vannozzi: Participated in all experiments, contributed to the writing of the manuscript.

G.Breghi: Coordinate the whole study, contributed to the writing of the manuscript.

A. Briganti: Coordinated the data analysis, supervised the clinical phase of the study, contributed to the writing of the manuscript.

\section{Ethics}

None of the authors of this paper does have a financial or personal relationship with other people or organizations that could inappropriately influence or bias the content of the paper.

\section{References}

Ansah, O.B., M. Raekallio and O. Vainio, 1998. Comparison of three doses of dexmedetomidine with medetomidine in cats following intramuscular administration. J. Vet. Pharmacol Ther., 21: 380-387. DOI: 10.1046/j.1365-2885.1998.00155.x

Bednarski, R.M., 2011. Anesthesia Management of Dogs and Cats. In: Essentials of Small Anesthesia and Analgesia, 2nd Edn., John Wiley \& Sons, INC. West Sussex, UK, ISBN-10: 9780813812366, pp: 376.

Belda, E., F.G. Laredo, M. Escobar, A. Agut and J.C. Mansel et al., 2009. Anaesthetic and cardiorespiratory effects of romifidine/ketamine combinations in cats. Vet. Anesth. Analg., 36: 229-307. DOI: $10.1111 /$ j.1467-2995.2009.00460.x 
Bley, C.R., G. Neiger-Aeschbacher, A. Busato and Urs Schatzmann, 2004. Comparison of perioperative racemic methadone, levo-methadone and dextromoramide in cats using indicators of postoperative pain. Vet. Anaesth. Analg., 31: 175-182. DOI: 10.1111/j.1467-2987.2004.00148.x

Bortolami, E., J.C. Murrell and L.S. Slingsby, 2013. Methadone in combination with acepromazine as premedication prior to neutering in cat. Vet. Anaesth. Analg., 40: 181-193. DOI: 10.1111/j.1467-2995.2012.00736.x

Chabot-Doré, A.J., D.J. Schuster, L.S. Stone and G.L. Wilcox, 2014. Analgesic synergy between opioid and $\alpha_{2}$-adrenoceptors. Br. J. Pharmacol., 172: 388-402. DOI: $10.1111 / \mathrm{bph} .12695$

Codd, E.E., R.P. Shank, J.J. Schupsky and R.B. Raffa, 1995. Serotonin and norepinephrine uptake inhibiting activity of centrally acting analgesics: Structural determinants and role in antinociception. J. Pharmacol. Exp. Ther., 274: 1263- 1270. PMID: 7562497

Court, M.H. and D.J. Greenblatt, 2000. Molecular genetic basis for deficient acetaminophen glucuronidation by cats: UGT1A6 is a pseudogene and evidence for reduced diversity of expressed hepatic UGT1A isoforms. Pharmacogenetics, 10: 355-369. PMID: 10862526

Dart, C.M., 1999. Advantages and disadvantages of using alpha $a_{2}$ agonist in veterinary practice. Aust. Vet. J., 77: 720-721. DOI: 10.1111/j.1751-0813.1999.tb12907.x

Dobromylskyj, P., 1993. Assessment of methadone as an anaesthetic premedicant in cats. J. Small Anim. Pract., 34: 604-608. DOI: $10.1111 /$ j.1748-5827.1993.tb02588.x

Dyson, D.H., 1988. Efficacy of lidocaine hydrochloride for laryngeal desensitization: A clinical comparison of techniques in the cat. J. Am. Vet. Med. Ass., 192: 1286-1288. PMID: 3391852

EMEA, 2009. Dexdomitor. In Dexdomitor Ed Report, E.P.A. European Medicines Agency.

Fishamn, S.M., B. Wilsey, G. Mahajan and P. Molina, 2002. Methadone reincarnated: Novel clinical applications with related concerns. Pain Med., 3: 339-348. DOI: 10.1046/j.1526-4637.2002.02047.x

Gorman, A.L., K.J. Elliot and C.E. Inturrisi, 1997. The $\mathrm{d}$ - and 1-isomers of methadone bind to the noncompetitive site on the N-Methyl-D-Aspartate (NMDA) receptor in rat forebrain and spinal cord. Neurosci. Lett., 223: 5-8. DOI: 10.1016/S0304-3940(97)13391-2

Granholm, M., B.C. McKusikc, F.C. Westerholm and J.C. Aspegrén, 2006. Evaluation of the clinical efficacy and safety of dexmedetomidine or medetomidine in cats and their reversal with atipamezole. Vet. Anaesth. Analg., 33: 214-223. DOI: $10.1111 /$ j.1467-2995.2005.00259.x
Grint, N.J., J. Burford, A.H.A. Dugdale, 2009. Investigating medetomidine-buprenorphine as preanaesthetic medication in cats. J. Small Anim. Pract., 50: 73-81.

DOI: $10.1111 /$ j.1748-5827.2008.00688.x

Herbert, B.A.G., P.M.G. Ramaciotti, F. Ferrari, L.H. Navarro and G. Nakamura et al., 2007. The use of dexmedetomidine in neurosurgery. Rev. Bras Anestesiol., 2: 223-231. PMID: 19466357

Jordan, B.A., I. Gomes, C. Rios, J. Filipovska and L.A. Devi et al., 2003. Functional interaction between $\mu$ opioid and $\alpha_{2 \mathrm{~A}}$-adrenergic receptors. Molecular Pharmacology, 64: 1317-1324. DOI: $10.1124 / \mathrm{mol} .64 .6 .1317$

Kallio, A., M. Scheinin, M. Koulu, R. Ponkilainen and H. Ruskoaho, 1989. Effects of dexmedetomidine, a selective $\quad \alpha 2$-adrenoceptor agonist, on hemodynamic control mechanisms. Clin. Pharmacol. Ther., 46: 33-42. DOI: $10.1038 /$ clpt.1989.103

Kilpatrick, G.J. and T.W. Smith, 2005. Morphine-6glucuronide: Actions and mechanisms. Med. Res. Rev., 25: 521-544. DOI: 10.1002/med.20035

Lamont, L.A., B.J. Bulmer, K.A. Grimm, W.J. Tranquilli and D.D. Sisson, 2001. Cardiopulmonary evaluation of the use of medetomidine hydrochloride in cats. Am. J. Vet. Res., 62: 1745-1762. DOI: $10.2460 /$ ajvr.2001.62.1745

Leppänen, M.K., B.C. McKusick, M.M. Granholm, F.C. Westerholm and R. Tulamo et al., 2006. Clinical efficacy and safety of dexmedetomidine and buprenorphine, butorphanol or diazepam for canine hip radiography. J. Small Anim. Pract., 47: 663-669. DOI: $10.1111 /$ j.1748-5827.2006.00030.x

MacDonald, E., M. Scheinin, H. Scheinin and R. Virtanen, 1991. Comparison of the behavioral and neurochemical effects of the two optical enantiomers of medetomidine, a selective alpha-2adrenoceptor agonist. J. Pharmacol., Exp. Ther., 259: 848-854. PMID: 1682487.

Mendes, G.M., A.L. Selmi, G.R. Barbudo-Selmi, B.T. Lins and J.P. Figueiredo, 2003. Clinical use of dexmedetomidine as premedicant in cats undergoing propofol-sevoflurane anaesthesia. J. Feline Med. Surg., 5: 265-270.

DOI: $10.1016 / \mathrm{S} 1098-612 \mathrm{X}(03) 00053-6$

Moffat, K., 2008. Addressing canine and feline aggression in the veterinary clinic. Vet. Clin. North Am. Small Anim. Pract., 38: 983-1003.

DOI: 10.1016/J.CVSM.2008.04.007

Mollenhoff, A., I. Nolte and S. Kramer, 2005. Antinociceptive efficacy of carprofen, levomethadone and buprenorphine for pain relief in cats following major orthopedic surgery. Vet. Med. A Physiol. Pathhol. Clin. Med., 52: 186-198. PMID: 15882404 
Monteiro, E.R., C.D.N. Figueroa, J.C. Choma, Daniela Campagnol and Carlos M. Bettini et al., 2008. Effects of methadone, alone or in combination with acepromazine or xylazine, on sedation and physiologic values in dogs. Vet. Anaesth. Analg., 35: 519-527.

DOI: $10.1111 / \mathrm{j} .1467-2995.2008 .00412 . x$

Ossipov, M.H., S. Harris, P. Lloyd, E. Messineo, B.S. Lin and J. Bagley et al., 1990. Antinociceptive interaction between opioids and medetomidine: systemic additivity and spinal synergy. Anesthesiology, 73: 1227-1235. PMID: 1978990

Overland, A.C., K.F. Kitto, A.J. Chabot-Doré, P.E. Rothwell and C.A. Fairbanks et al., 2009. Protein kinase $\mathrm{C}$ mediates the synergistic interaction between agonists acting at $\alpha 2$-adrenergic and delta-opioid receptors in spinal cord. J. Neurosci., 29: 13264-13273. DOI: 10.1523/JNEUROSCI.1907-09.2009

Pascoe, P.J., 2000. Opioid analgesics. Vet. Clinics North America Small Anim. Pract., 30: 757-772. DOI: $10.1016 / \mathrm{S} 0195-5616(08) 70005-6$

Pertovaara, A., 1993. Antinociception induced by alpha-2-adrenoceptor agonists, with special emphasis on medetomidine studies. Progress Neurobiol., 40: 691-709. DOI: 10.1016/0301-0082(93)90011-G

Pypendop, B.H., L.S. Barter, S.D. Stanley and J.E. Ilkiw, 2011. Hemodynamic effects of dexmedetomidine in isoflurane-anesthetized cats. Vet. Anaesth. Analg., 38: $555-567$.

DOI: 10.1111/j.1467-2995.2011.00663.x

Robertson, S.A., P.M. Taylor, B.D. Lascelles and M.J. Dixon, 2003. Changes in thermal threshold response in eight cats after administration of buprenorphine, butorphanol and morphine. Vet. Rec., 153: 462-465. DOI: $10.1136 / \mathrm{vr} .153 .15 .462$

Santos, L.C.P., J.W. Ludders, H.N. Erb, K.L. Basher and P. Kirch et al., 2010. Sedative and cardiorespiratory effects of dexmedetomidine and buprenorphine administered to cats via oral transmucosal or intramuscular routes. Vet. Anaesth. Analg., 37: 417-424. DOI: $10.1111 / \mathrm{j} .1467-2995.2010 .00555 . \mathrm{X}$

Selmi, A.L., G.M. Mendes, B.T. Lins, J.P. Figueiredo and G.R. Barbudo-Selmi, 2003. Evaluation of the sedative and cardiorespiratory effects of dexmedetomidine, dexmedetomidine-butorphanol and dexmedetomidine-ketamine in cats. J. Am. Vet. Med. Assoc., 222: 37-41.

DOI: $10.2460 /$ javma.2003.222.37

Shaughnessy, M.R. and E.H. Hofmeister, 2014. A systematic review of sevoflurane and isoflurane minimum alveolar concentration in domestic cats. Vet. Anaesth. Analg., 41: 1-13.

DOI: $10.1111 /$ vaa. 12083
Sinclair, M.D., M.R. O’Grady, C.L. Kerr and Wayne N McDonell, 2003. The echocardiographic effects of romifidine in dogs with and without prior or concurrent administration of glycopyrrolate. Vet. Anaesth. Analg., 4: 211-219.

DOI: $10.1046 / j .1467-2995.2003 .00122 . x$

Slingsby, L.S. and P.M. Taylor, 2008. Thermal antinociception after dexmedetomidine administration in cats: A dose-finding study. J. Vet. Pharmacol Ther., 31: 135-42. DOI: $10.1111 /$ j.1365-2885.2007.00931.x.

Slingsby, L.S., P.M. Taylor and T. Monroe, 2009. Thermal antinociception after dexmedetomidine administration in cats: A comparison between intramuscular and oral transmucosal administration. J. Feline Med. Surg., 11: 829-834. DOI: 10.1016/j.jfms.2009.03.009

Staffieri, F., P. Centonze, G. Gigante, L. De Pietro and A. Crovace, 2013. Comparison of the analgesic effects of robenacoxib, buprenorphine and their combination in cats after ovariohysterectomy. Vet. J., 197: 363-367. DOI: 10.1016/j.tvj1.2013.01.018

Steffey, E.P. and K.R. Mama, 2007. Inhalation Anesthetics. In: Lumb and Jones' Veterinary Anesthesia and Analgesia 4th Edn., Blackwell Publishing, Oxford, UK, ISBN-10: 9780781754712, pp: 287.

Taylor P.M., S.A. Robertson and M.J. Dixon, 2001. Morphine, pethidine and buprenorphine disposition in the cat. Vet. Pharmacol. Ther., 24: 391-398. PMID: 11903869.

Taylor, P.M. and S.A. Robertson, 2004. Pain management in cats-past, present and future. Part 1. The cat is unique. J. Feline Med. Surg., 6: 313-320. DOI: $10.1016 /$ j.jfms.2003.10.003

Teppema, L.J., E. van Dorp, B.M. Gourabi, J.W. van Kleef and A. Dahan, 2008. Differential effect of morphine and morphine-6-glucuronide on the control of breathing in the anesthetized cat. Anesthesiology, 109: 689-697. DOI: $10.1097 / A L N .0 b 013 \mathrm{e} 31818631 \mathrm{bd}$

Wright, B.D., 2002. Clinical pain management techniques for cats. Clinical Techniques Small Anim. Pract., 17: 151- 157.

DOI: 10.1053/svms.2002.36609

Xiao, Y., R.D. Smith, F.S. Caruso and K.J. Kellar, 2001. Blockade of rat alpha3beta4 nicotinic receptor function by methadone, its metabolites and structural analogs. J. Pharmacol. Exp. Ther., 229: 366-371. PMID: 11561100 